\title{
Sesamoids and accessory ossicles of the foot: anatomical variability and related pathology
}

\author{
O. Kenechi Nwawka • Daichi Hayashi • Luis E. Diaz • \\ Ajay R. Goud • William F. Arndt III • Frank W. Roemer • \\ Nagina Malguria $\cdot$ Ali Guermazi
}

Received: 24 May 2013 / Revised: 13 July 2013 / Accepted: 17 July 2013 / Published online: 5 September 2013

(C) The Author(s) 2013. This article is published with open access at Springerlink.com

\begin{abstract}
Sesamoids and accessory ossicles seen in the foot vary widely in their prevalence and appearance. Occasionally, these bones may be associated with painful syndromes, due to various pathologies, including trauma, infection, inflammation, degeneration and others. However, symptomatic accessory and sesamoid bones are rare, and search for additional pathology should be performed. Although the clinical significance of these osseous structures is probably minor, clinicians very commonly ask about these bones, which may originate an unnecessary work-up. Therefore, knowledge of their presence and morphological variations is important to prevent misinterpreting them as fractures - a common error. Finally, it may be very difficult to distinguish between incidental variants and truly symptomatic ones. Radiological studies provide insight regarding the presence and pathology involving these bones. This review describes an overview of the anatomy of sesamoids and accessory ossicles in the foot, and provides a pictorial review of their pathological conditions, including trauma, sesamoiditis, osteomyelitis, osteoarthritis and pain syndromes. Radiological studies including radiography, ultrasound, scintigraphy, computed
\end{abstract}

O. K. Nwawka • D. Hayashi $(\bowtie) \cdot$ L. E. Diaz $\cdot$ F. W. Roemer

A. Guermazi

Department of Radiology, Boston Medical Center, Boston University

School of Medicine, 820 Harrison Avenue, FGH Building, 3rd Floor,

Boston, MA 02118, USA

e-mail: dhayashi@bu.edu

L. E. Diaz $\cdot$ A. R. Goud $\cdot$ W. F. Arndt III $・$ N. Malguria

Department of Radiology, VA Healthcare System, West Roxbury,

MA 02132, USA

D. Hayashi

Department of Radiology, Bridgeport Hospital, Yale University

School of Medicine, Bridgeport, CT 06610, USA

F. W. Roemer

Department of Radiology, University of Erlangen, Erlangen,

Germany tomography (CT) and magnetic resonance imaging (MRI) provide useful information which should be used in concert with clinical findings to guide patient management.

Teaching points

- Sesamoids and accessory ossicles seen in the foot vary widely in their prevalence and appearance.

- Pathology of these bones includes trauma, sesamoiditis, infection, osteoarthritis and pain syndromes.

- Radiography, ultrasound, scintigraphy, CT and MRI provide information regarding the pathology of these bones.

Keywords Sesamoids · Accessory ossicles $\cdot$ Foot $\cdot$ MRI · CT $\cdot$ Radiography

\section{Introduction}

Sesamoids are osseous structures partially or totally embedded in a tendon. Their function is to protect the tendon from injury by reducing friction. In contrast, accessory ossicles are supernumerary bones that commonly derive from unfused primary or secondary ossification centres [1]. They are thought to be normal variants with no definite known function. However, both sesamoids and accessory ossicles may be associated with pathological conditions.

Sesamoids and accessory ossicles share several imaging characteristics: They are usually small, well-corticated, ovoid or nodular, may be bipartite or multipartite, and are found close to a bone or a joint. The presence of these osseous structures is usually incidental. Both sesamoids and accessory ossicles may be unilateral or bilateral, and are subject to significant morphological variations. Understandably, this may make the recognition of pathological conditions challenging. Although it is difficult to determine the symptomatic nature of these bones, imaging provides important diagnostic information to be considered in the clinical work-up. This article aims to review the 
normal anatomy of these bony structures, and to discuss their most common associated pathological conditions.

\section{Sesamoids}

The sesamoids seen in the foot include the hallucal sesamoids, lesser metatarsal sesamoids and interphalangeal joint sesamoid of the great toe (Fig. 1). Technically, os peroneum can be considered a sesamoid but it will be described in the ossicles section in this manuscript since it is anatomically classified as an accessory ossicle. A summary of the names of the sesamoids and accessory bones, their locations and prevalence is presented in Table 1 .

\section{Hallucal sesamoids}

The hallucal sesamoids are always present at the plantar aspect of the first metatarsal head, and are a constant in humans. The

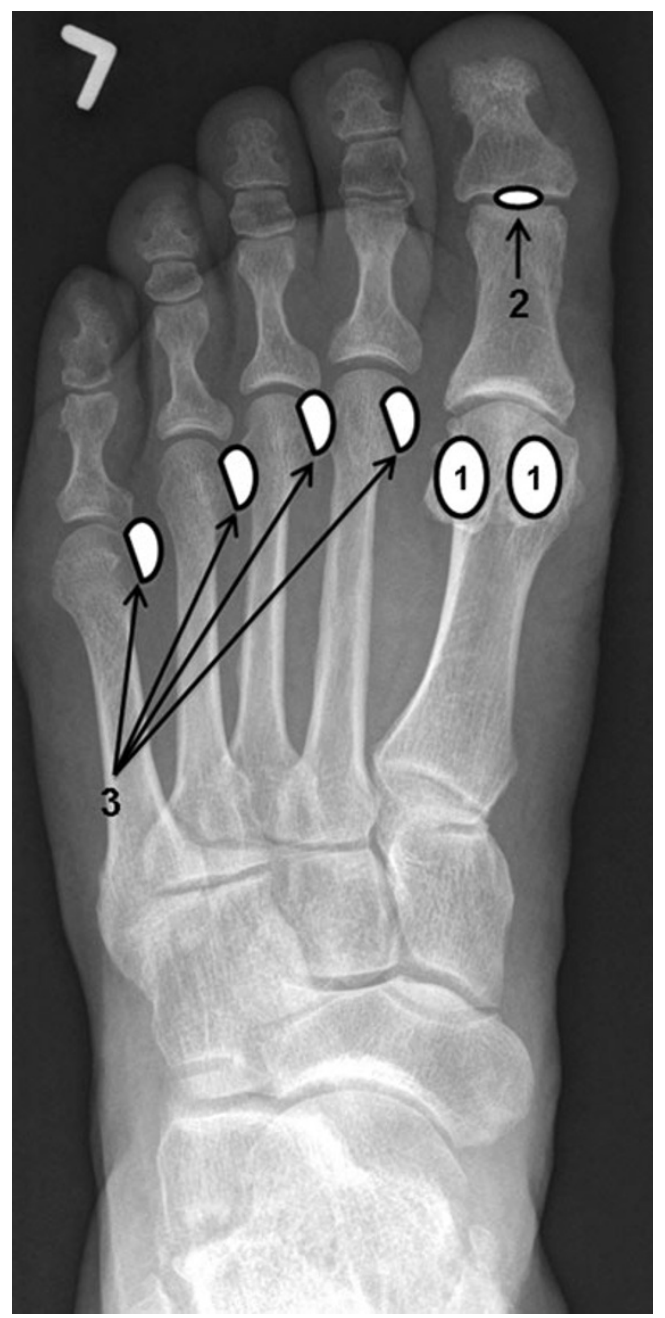

Fig. 1 Sesamoids of the foot. AP radiograph depicting the sites of hallucal (1), interphalangeal joint (2) and lesser metatarsal (3) sesamoids
AP and axial view radiographs of the foot best depict the hallucal sesamoids (Fig. 2). The medial sesamoid commonly shows bipartite variation [2]. Bipartite sesamoid fragments tend not to fit together perfectly, which aids differentiation from a fracture (Fig. 3) (Table 2). Associated pathology related to the hallucal sesamoids is not uncommon and in addition to fracture includes infection, arthritis and osteonecrosis [3].

\section{Lesser metatarsal sesamoids}

Anatomically, sesamoids at the second through fifth metatarsals appear to be embedded in the plantar aspect of the joint capsule and may also be multiple or multipartite. The prevalence of sesamoids at the second through fourth metatarsals has been documented at $0.4 \%$ at the second metatarsal, $0.2 \%$ at the third, $0.1 \%$ at the fourth, and up to $4.3 \%$ at the fifth metatarsal [4]. If present, these sesamoids are best evaluated on AP and oblique radiographs of the foot (Fig. 4). Pathology associated with these sesamoids is very rare, although infection from direct spread from adjacent soft tissue is possible.

\section{Interphalangeal joint sesamoid}

As its name implies, the interphalangeal joint sesamoid is seen at the plantar aspect of the interphalangeal (IP) joint of the first digit of the foot. It is embedded within the joint capsule and the presence of an ossified sesamoid may alter biomechanics and limit motion in the joint [5]. The prevalence of this sesamoid has been reported variably at $2-13 \%$ in its ossified form [4]. A review of post-mortem cases reports an anatomically identified IP joint nodule in up to $73 \%$ of cases [6]. These bones are best imaged on an AP radiograph of the foot or toes. A potential serious pathology associated with this sesamoid is its interposition into a dislocated IP joint, making it irreducible [7, 8].

\section{Ossicles}

The most common accessory bones described in the foot are the os trigonum, os peroneum and os naviculare [9]. Others found in the foot include the os intermetatarseum, os vesalianum, os supranaviculare, os supratalare, os talotibiale and os calcaneus secundarium (Fig. 5).

\section{Os trigonum}

Os trigonum is located posterior to the talus. The reported prevalence of the os trigonum is quite variable, from 7 to $25 \%$ $[9,10]$. They are best seen on lateral radiographs of the foot and ankle and may be round, oval or triangular and may have a synchondrosis with the posterolateral talus $[10,11]$. The os trigonum may be symptomatic in different forms related to its 
Table 1 Location and reported prevalence of the sesamoid and accessory ossicles of the foot

\begin{tabular}{|c|c|c|}
\hline Name & Location & $\begin{array}{l}\text { Reported prevalence } \\
\text { [references] }\end{array}$ \\
\hline
\end{tabular}

Sesamoids

Hallucal

Lesser metatarsal

Interphalangeal joint

Ossicles

Os trigonum
Os peroneum

Accessory avicular

Os intermetatarseum

Os vesalianum

Os supranaviculare

Os supratalare

Os talotibiale

Os calcaneus secundarium
Plantar aspect of the first metatarsal head

Plantar aspect of the second through fifth metatarsals

Plantar aspect of the interphalangeal joint of the first digit of the foot

Posterior to the talus

At the cuboid tunnel adjacent to the calcaneocuboid joint, within the peroneus longus tendon

Adjacent to the tarsal navicular, within the distal posterior tibial tendon

Between the first and second metatarsal

Proximal to the base of the fifth metatarsal, within the peroneus brevis tendon

Above the talonavicular joint

Above the neck of the talus

Anterior to the tibiotalar joint

Adjacent to the anterior calcaneal process
$1.0-3.5 \%[4,19,20]$

$0.2-2.4 \%[4,19,20]$

Always present

$0.4 \%$ (second);

$0.2 \%$ (third);

$0.1 \%$ (fourth)

Up to $4.3 \%$ (fifth) [4]

$2-13 \%[4]$

$7-25 \%[9,10]$

Up to $26 \%[13,14]$

$2-21 \%[9,15]$

$1-13 \%[9,13]$

$0.1-1 \%[17]$

$0.5 \%[19]$

$0.6-7 \%[21]$ size, stability and other local issues. Fracture of an os trigonum itself is extremely rare [12]. A common differential for the os trigonum is a Shepherd fracture, i.e. a fracture of the lateral process of the talus. Pathology at the os trigonum may be a cause of posterior ankle impingement syndrome [10, 11, 13].

\section{Os peroneum}

The os peroneum is located in the region of the cuboid tunnel near the calcaneocuboid joint. It is embedded within the peroneus longus tendon, technically making it a sesamoid. Although present in everyone in at least a cartilaginous form [13], this ossicle in its fully ossified form is found in up to $26 \%$ of the population $[13,14]$. On radiographs, it is best identified in an oblique view of the foot. It may appear round or oval. It is bipartite in approximately $30 \%$ of cases, and bilateral in approximately $60 \%$ [14]. The os peroneum may become painful, may fracture, and also may become displaced. Displacement is an indirect sign of a peroneus longus tendon tear, described later in the article.

\section{Accessory navicular}

There are three reported types based on morphology. Type I $(30 \%)$ is an oval or round sesamoid located within the distal posterior tibial tendon. It may be separated up to $5 \mathrm{~mm}$ from the navicular tuberosity. Type II is the most common variant (50\%) and is known as the os naviculare. It is a triangular or heart-shaped unfused accessory ossification centre, separated from the tuberosity by a $1-2 \mathrm{~mm}$ wide synchondrosis. Type III $(20 \%)$ is a prominent tuberosity, thought to be a fused type II accessory navicular bone. The accessory navicular bone is the 


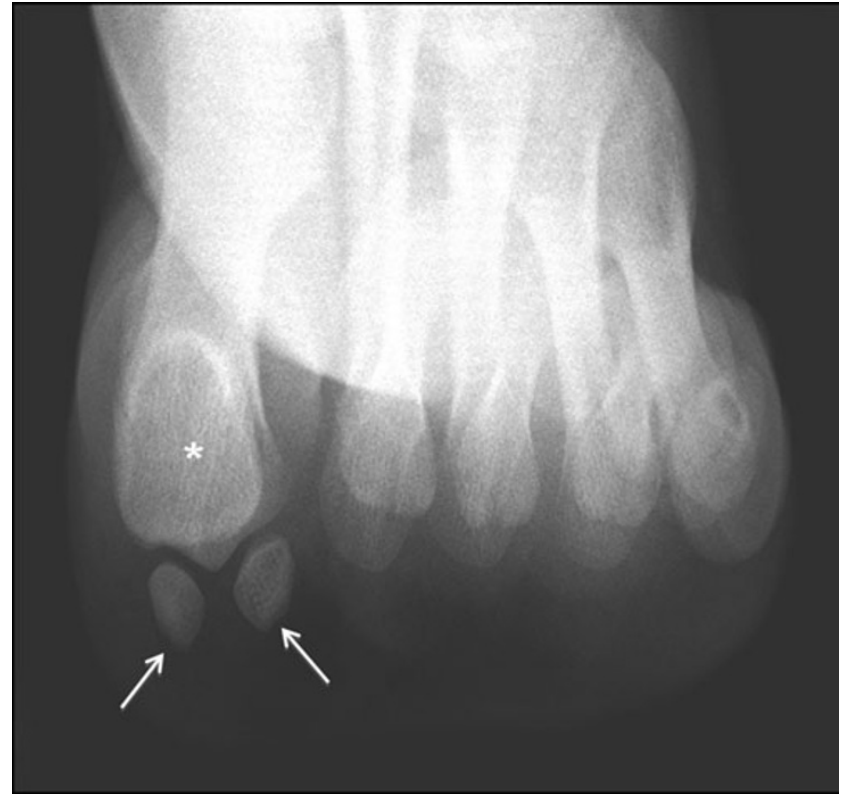

Fig. 2 Hallucal sesamoids. Axial view radiograph of the forefoot shows normal hallucal sesamoids (arrows) and their articulation with the first metatarsal head (asterisk)

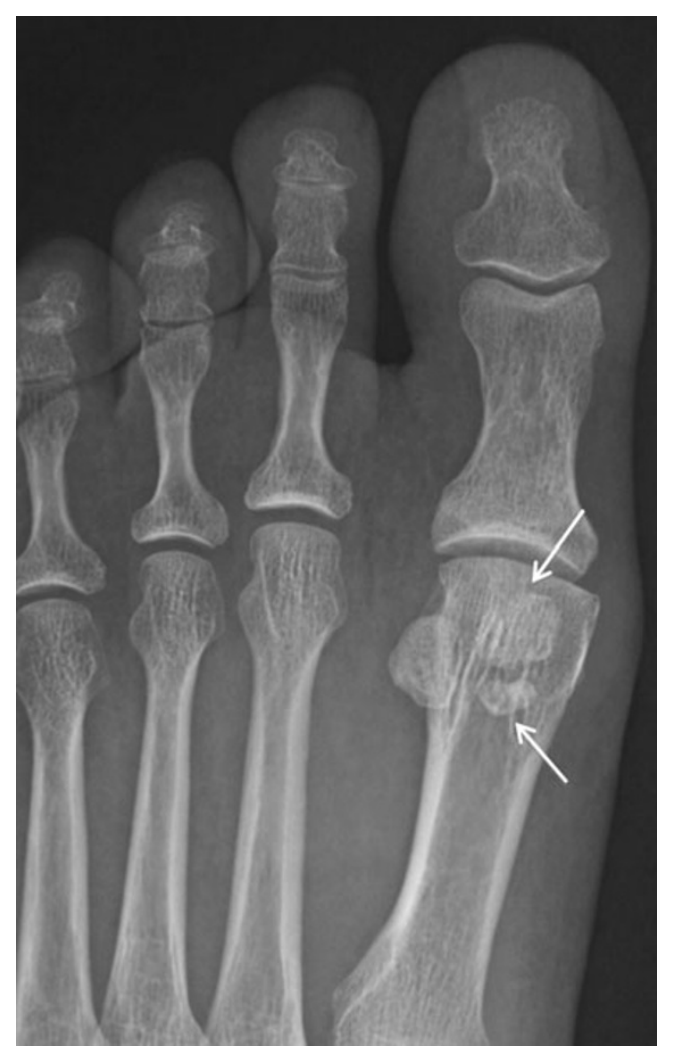

Fig. 3 Bipartite hallucal sesamoid. The bipartite fragments of the medial hallucal sesamoid are shown. Unlike a normal bipartite sesamoid, the fragments do not fit together perfectly like the pieces of a puzzle
Table 2 Radiological clues to differentiate a fractured hallucal sesamoid and bipartite hallucal sesamoid

Single medial sesamoid

Bipartite medial sesamoid with a fracture
Slightly larger than the lateral sesamoid, whereas the

Show a sharp, radiolucent, uncorticated line between the two fragments

The two fragments often fit together like pieces of a puzzle

A ${ }^{99 \mathrm{~m}} \mathrm{Tc}-\mathrm{MDP}$ bone scan will show increased uptake oedema in a recently fractured sesamoid
MRI may show bone marrow

\section{Much larger than the}

lateral sesamoid

Two corticated components

The two components do not fit like pieces of a puzzle

A ${ }^{99 m}$ Tc-MDP bone scan should be normal

No MRI signal abnormality

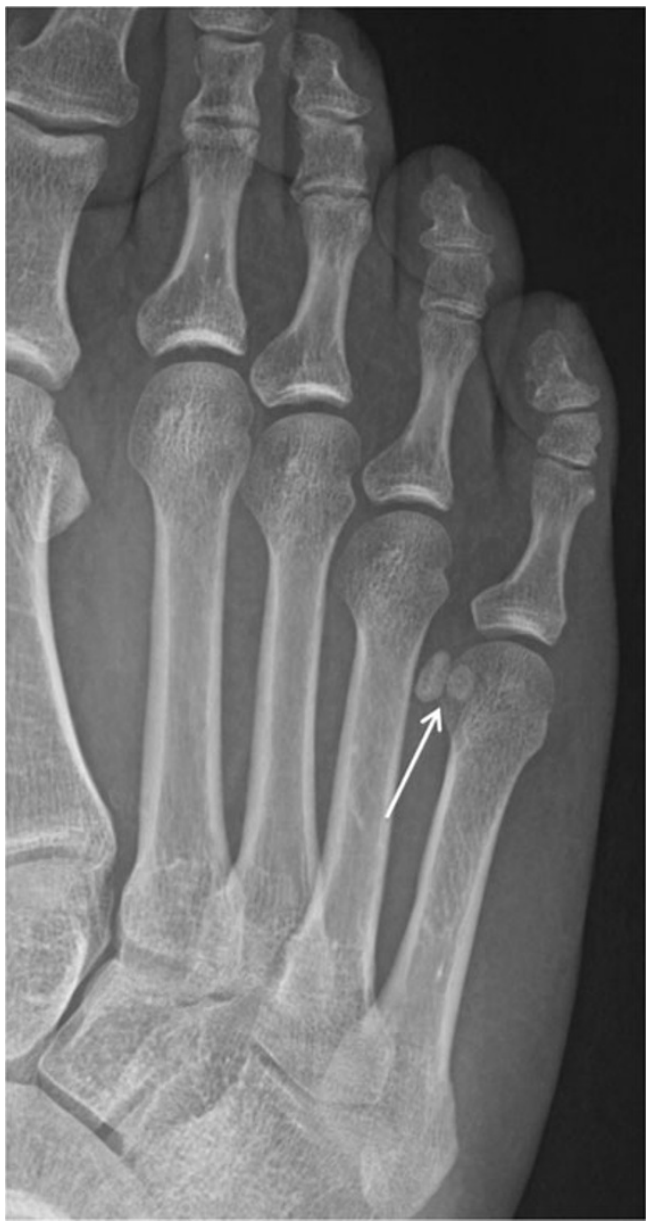

Fig. 4 Bipartite lesser metatarsal sesamoid. Bipartite fifth metatarsal sesamoid is shown (arrow), with ell-corticated rounded fragments that do not fit together 


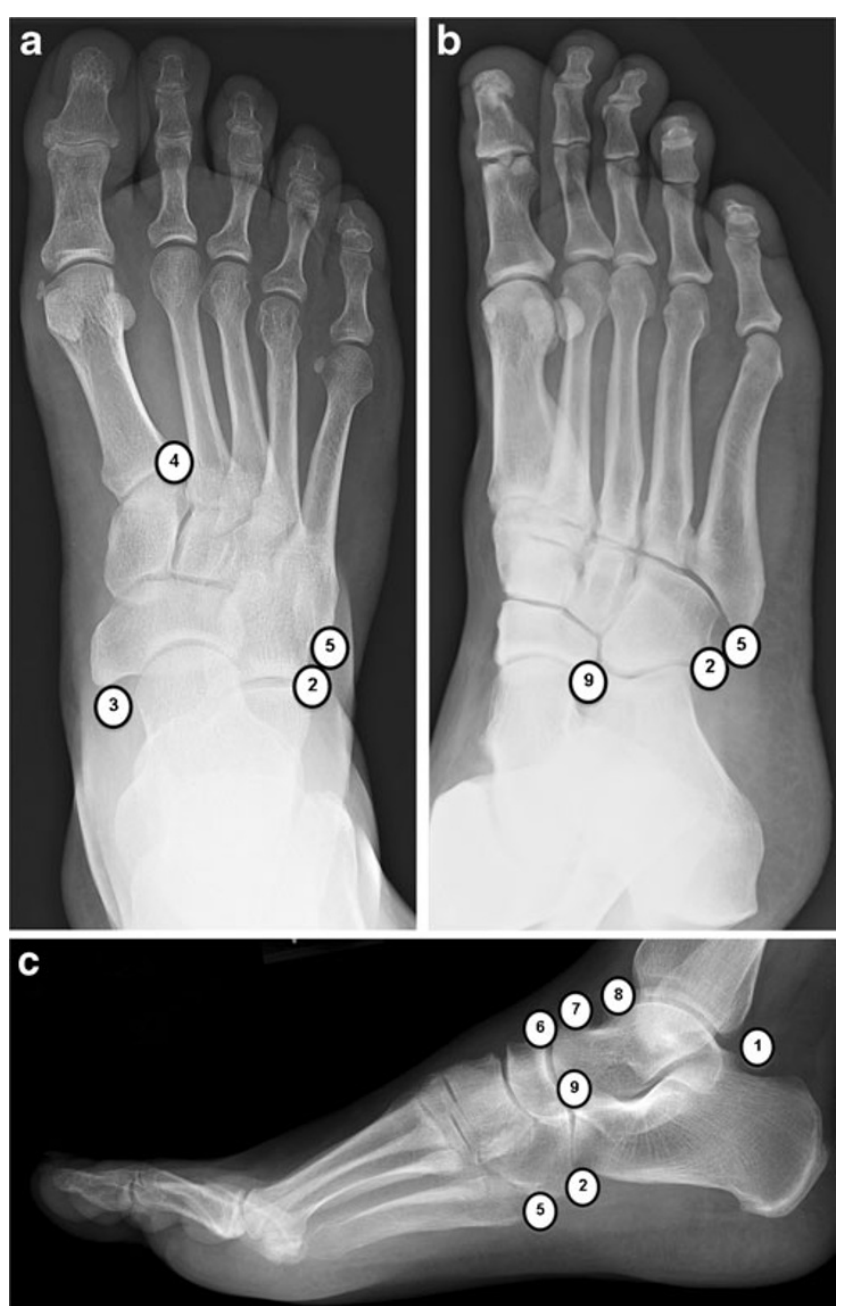

Fig. 5 Accessory ossicles of the foot. AP (a), oblique (b) and lateral (c) radiographs depicting the sites of the most common accessory ossicles in the foot. 1 Os trigonum, 2 os peroneum, 3 os naviculare, 4 os intermetatarseum, 5 os vesalianum 6 os supranaviculare, 7 os supratalare, 8 os talotibiale, 9 os calcaneus secundarium

second most common accessory bone of the foot, with reported prevalence from 2 to $21 \%[9,15]$. It is bilateral in $50 \%$ of cases. It is best seen on an AP radiograph of the foot. Of the three variations, type II is most commonly symptomatic $[13,16]$.

\section{Os intermetatarseum}

This ossicle is most commonly located between the first and second metatarsal [8]. Radiographic studies report a prevalence of $1-7 \%$, while anatomical studies demonstrate a higher prevalence of up to $13 \%[9,13]$. It is best visualised on an AP foot radiograph and usually appears oval or round, but may also be spindle-shaped and attached to a metatarsal. Although this os rarely has associated pathology, its location may cause it to be confused with a fracture of the second metatarsal such as in Lisfranc injuries (Fig. 6). Lack of a donor site, soft tissue swelling and osseous malalignment my help differentiate this normal variant from a fracture.
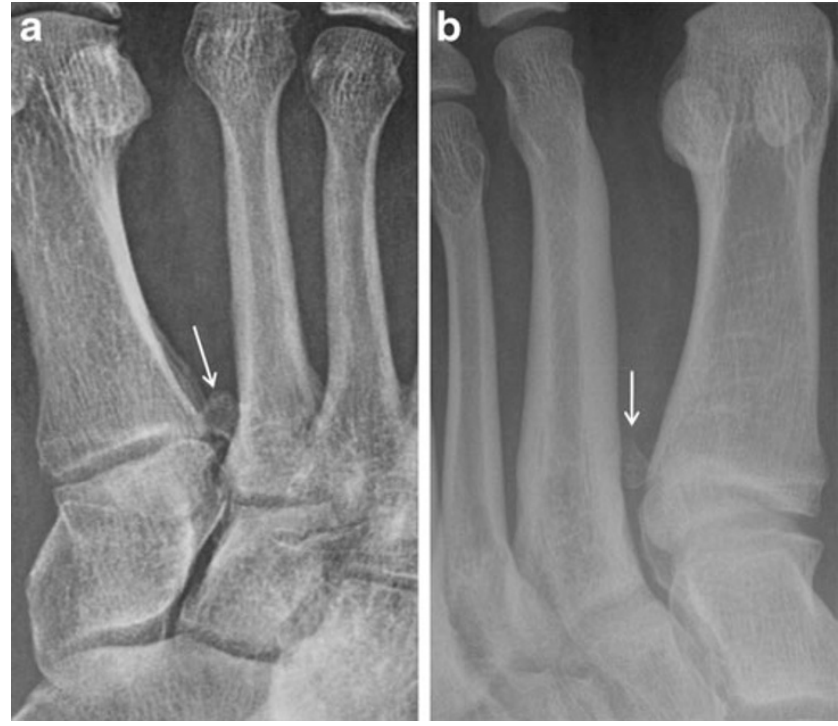

Fig. 6 Os intermetatarseum. Oblique radiographs of the foot from two different patients show rounded (a) and spindle (b) configurations of the os intermetatarseum (arrows) located between the base of the first and second metatarsals. This may sometimes be mistaken for a bone fragment secondary to a remote trauma

\section{Os vesalianum}

The os vesalianum is located proximal to the base of the fifth metatarsal, found within the peroneus brevis tendon and may articulate with the cuboid. The reported prevalence of an os vesalianum is between 0.1 and $1 \%$ [17]. It is best seen on an oblique radiograph of the foot. The os vesalianum is rarely a source of pathology, but painful conditions similar to os peroneum syndrome have been described [18]. A differential consideration for an os vesalianum is a fracture of the base of the fifth metatarsal.

Os supranaviculare, os supratalare and os talotibiale

These rare ossicles are all located adjacent to the dorsal talus $[4,19,20]$. The os supranaviculare may fuse with the navicular to form a spur of no clinical significance [4]. These ossicles are rarely associated with painful conditions and, although their appearance may occasionally be challenging radiographically, the lack of a donor site, soft tissue swelling and focal tenderness should help to differentiate them from avulsion fractures.

\section{Os calcaneus secundarium}

This ossicle is located between the anteromedial aspect of the calcaneus, the cuboid, the talar head and the tarsal navicular. The incidence of the os calcaneus secundarium has been reported between 0.6 and $7 \%$ [21]. This rare ossicle is difficult to detect radiographically due to overlying structures, but can be visualised on CT. The os calcaneus secundarium has not 
been shown to have any clinical significance [21]. However, its location makes it difficult to differentiate from a fracture of the anterosuperior calcaneal process [22]. MRI may be useful to detect bone marrow oedema related to a fracture in this location.

\section{Pathological conditions in sesamoids and accessory ossicles of the foot}

Both sesamoid bones and accessory ossicles can be affected by trauma, infection, degenerative disease and osteonecrosis. Due to their locations in the foot, the hallucal sesamoids and the os trigonum are more susceptible to trauma and fracture. Location also predisposes the hallucal sesamoids to infection, particularly via direct extension. Accessory ossicles with synchondroses such as the os naviculare and os trigonum are predisposed to degenerative change. Sesamoids embedded within high-use tendons such as the os peroneum are also susceptible to degenerative disease.

Radiological studies are useful in the identification of pathology localising to sesamoids and accessory ossicles. Radiographs confirm the presence of an ossified accessory bone, and fractures are commonly evident on X-rays. Cartilaginous or non-ossified accessory bones may be identified on ultrasound, which can also be useful in the evaluation of adjacent soft tissue for signs of inflammation and injury [23]. Scintigraphy, used in concert with radiographic findings, may be useful in the localisation of the cause of foot pain to a sesamoid or an accessory ossicle [3,13]. Although highly sensitive, technetium bone scans are not as specific and may show increased uptake in stress reaction, osteonecrosis, osteoarthritis, fracture and infection (Fig. 7). CT readily demonstrates fracture and degenerative changes at a synchondrosis or articulation, and can also evaluate for increased sclerosis as seen in osteonecrosis. However, MRI is most useful in the evaluation of pathology associated with sesamoids and accessory ossicles. MRI findings are relatively specific for infection, osteoarthritis and fracture, and MRI provides superior evaluation of adjacent soft tissues. Table 3 summarises the types of pathology that can affect the sesamoids and the accessory ossicles and radiological clues to diagnose them.

\section{Trauma}

Both sesamoids and accessory ossicles may simulate a fracture of a neighbouring bone or may undergo fracture themselves, either from acute or chronic repetitive trauma. As these osseous structures are themselves small, identification of injury may be difficult. Certain radiographic clues can be used to diagnose acute injury. A well-corticated structure with smooth borders is less likely to be secondary to acute injury, while an irregular fragment with poorly corticated margins is suggestive of a fracture (Fig. 8). Other clues one might look for include evidence of displacement, presence of a donor site, and soft tissue swelling. For example, differentiating between an os vesalianum and an avulsion fracture of the apophysis of the fifth metatarsal can be difficult. If the suspected bony fragment is separated from the metatarsal by a radiolucent line of constant width with a well-corticated edge on radiography, it is more likely to be an os vesalianum than a metatarsal avulsion fracture [24]. As another example, it may be challenging to distinguish between the os trigonum and a fracture of the lateral tubercle of the posterior process of the talus, the so-called Shepherd's fracture [25, 26]. The fragment is rarely displaced, making it difficult to differentiate it from a true os trigonum on radiography alone. Clinical correlation with focal tenderness is also useful in determining acute

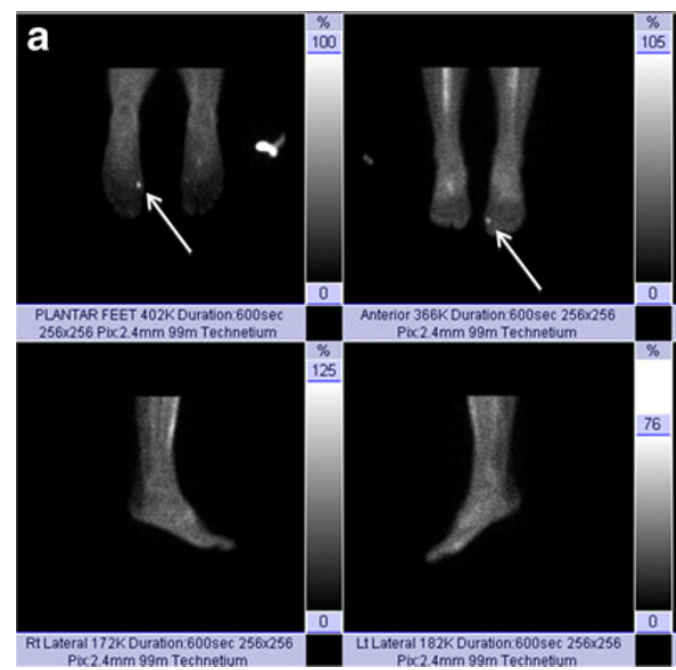

Fig. 7 Sesamoiditis. Bone scan of the bilateral feet (a) in a patient with plantar foot pain reveals nonspecific but intense tracer uptake localising to the medial hallucal sesamoid. AP radiograph at the first toe (b) reveals a
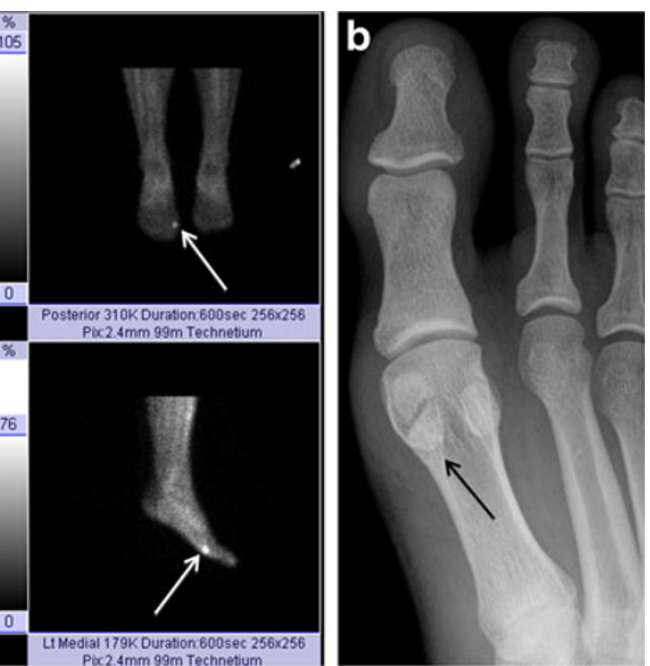

bipartite medial hallucal sesamoid with no diastasis, fragmentation or sclerosis. The patient was diagnosed with bony sesamoiditis 
Table 3 Pathological conditions associated with sesamoids and accessory ossicles of the foot and radiological clues to diagnose them

\begin{tabular}{|c|c|}
\hline Pathologies & Radiological clues \\
\hline Trauma (fracture) & $\begin{array}{l}\text { Irregular bony fragment with poorly cortic } \\
\text { margins; evidence of displacement; } \\
\text { presence of a donor site; soft tissue swel }\end{array}$ \\
\hline Sesamoiditis & $\begin{array}{l}\text { Bone marrow oedema isolated to the sesan } \\
\text { without changes in the metatarsal head } \\
\text { MRI; no increase in sclerosis on CT; } \\
\text { increased uptake on }{ }^{99 \mathrm{~m}} \mathrm{Tc}-\mathrm{MDP} \text { bone s }\end{array}$ \\
\hline Osteonecrosis & $\begin{array}{l}\text { Increased sclerosis on CT; bone marrow } \\
\text { oedema pattern (early) or diffusely } \\
\text { decreased signal (late) on MRI }\end{array}$ \\
\hline
\end{tabular}

Infection (osteomyelitis) Cortical destruction and adjacent soft tissue inflammation on radiograph (late stage disease); T2 hyperintensity of the marrow with corresponding T1 hypointensity, in addition to signs of inflammation in the surrounding soft tissues on non-enhanced MRI; intraosseous enhancement on contrast-enhanced MRI; possible fluidequivalent signal changes with peripheral enhancement representing intraosseous and soft tissue abscess formation

Degenerative disease (osteoarthritis)

Posterior ankle impingement syndrome

Painful os peroneum syndrome

Painful accessory navicular

Painful os intermetatarseum
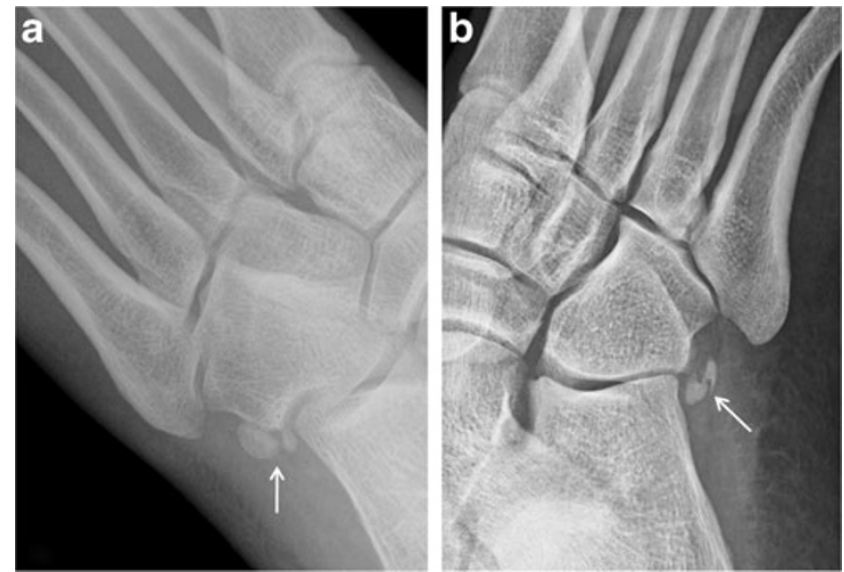

Fig. 8 Bipartite versus fractured os peroneum. a Bipartite os peroneum (arrow) with two well corticated, rounded ossicles at the calcaneocuboid articulation. b In comparison, a fragmented os peroneum (arrow) with irregular, angulated edges and displacement, consistent with a fracture

injury. When radiographic and clinical findings are equivocal, CT and MRI may help to identify true fractures by detecting oblique irregular interfaces which separate incompletely corticated fragments $[10,25,26]$.

Due to their locations in the foot, the hallucal sesamoids are more susceptible to trauma and fracture, with the medial sesamoid fractured more frequently $[3,27]$. Acute injury to the hallucal sesamoids can be seen in deceleration injuries transmitting a large amount of force through the sesamoids (Fig. 9), secondary to axial loading as in falling from a height, and also in association with plantar plate injuries [3]. Fractures of the os trigonum may be seen in forced plantar flexion $[10,11]$. A direct blow or inversion injury may result in fractures of the os
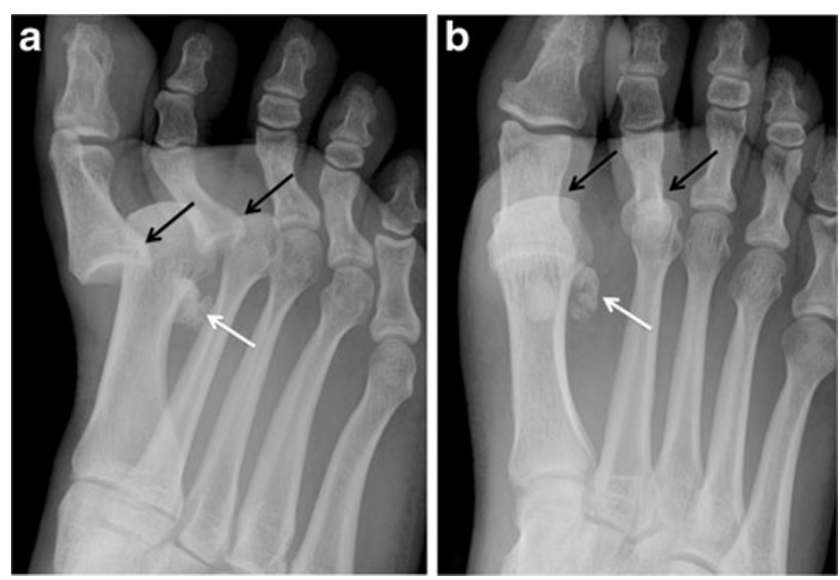

Fig. 9 Hallucal sesamoid fracture. Oblique (a) and AP (b) radiographs at the forefoot in a patient after deceleration injury. There are dorsal dislocations of the first and second metatarsophalangeal joints (black arrows), with a comminuted fracture of the lateral hallucal sesamoid (white arrows). Note that the sesamoid fracture pieces would fit together perfectly. The medial hallucal sesamoid is also fractured in this patient 

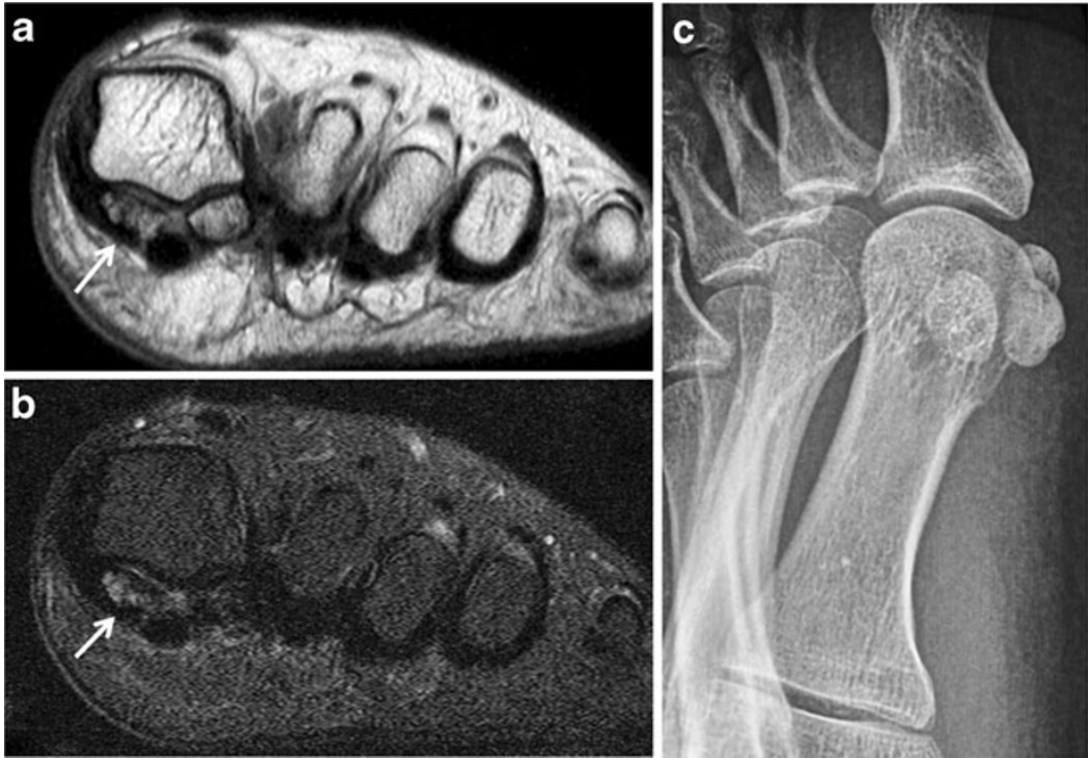

Fig. 10 Bony sesamoiditis in a patient with plantar forefoot pain. Short axis PD (a) and T2-weighted fat-saturated (b) images reveal a mild asymmetric pattern of bone marrow oedema confined to the medial hallucal sesamoid. Note lack of oedema in the lateral hallucal sesamoid,

peroneum [13], and proximal migration of an os peroneum suggests a tear of the peroneus longus tendon [23, 28].

\section{Sesamoiditis}

Chronic pain at the hallucal sesamoids may clinically be described as "sesamoiditis", a term that encompasses the symptoms from pathology at the hallux sesamoids complex [13]. Chronic pain can be caused by stress fracture, stress reaction, osteoarthritis first metatarsal head and surrounding soft tissues. Oblique sesamoid radiograph (c) shows no discernible abnormality. These results suggest bony sesamoiditis or stress reaction

and osteonecrosis of the sesamoids, as well as tendinosis and capsular inflammation [27]. Repetitive and excessive axial loading in plantar flexion, such as in ballet dancing, running and even wearing high-heeled shoes, have also been postulated as risk factors for sesamoiditis [3, 27]. Excision of one sesamoid may cause abnormal biomechanical stress on the residual sesamoid [3], also increasing the risk of stress fracture and osteonecrosis.

MRI is particularly useful in the imaging of clinical sesamoiditis, with the ability to evaluate intrinsic osseous
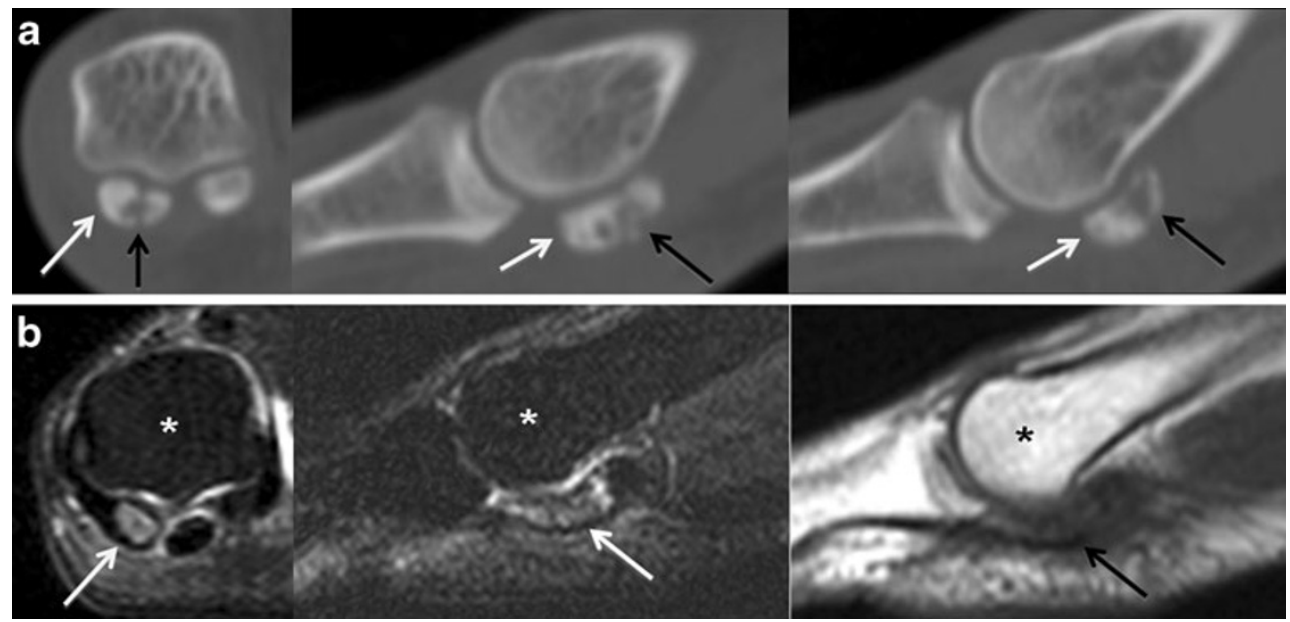

Fig. 11 Osteonecrosis. a Short-axis and sagittal CT images depict a fragmented medial hallucal sesamoid (black arrows), with increased density of the fragments (white arrows) which suggests post-traumatic osteonecrosis. b Short-axis and sagittal T2-weighted fat-saturated MRIs, and sagittal T1-weighted MRI obtained 1 month later show a pattern of severe bone marrow oedema (white arrows) with $\mathrm{T} 1$ hypointensity (black arrow) isolated to the medial hallucal sesamoid, and further collapse of the medial hallucal sesamoid, consistent with progression of osteonecrosis. Note normal marrow signal in the first metatarsal head (asterisks) 
and soft tissue abnormalities. On MRI, both sesamoiditis and osteonecrosis may show changes in the pattern of bonemarrow oedema isolated to the sesamoid, without changes in the metatarsal head to suggest osteoarthritis (Fig. 10). CT may be useful in differentiating between these two entities, as subtle increases in sclerosis detected on $\mathrm{CT}$ would favour a diagnosis of osteonecrosis (Fig. 11). ${ }^{99 \mathrm{~m}} \mathrm{Tc}-\mathrm{MDP}$ bone scan may help in identifying the presence of sesamoiditis as a focally increased uptake of the radioactive tracer [26].

\section{Infection}

Osteomyelitis affecting the sesamoids and accessory ossicles is most frequently secondary to direct extension [3]. The hallucal sesamoids may be infected secondary to extension from a soft tissue infection or from a septic joint [27]. Radiographs classically are only sensitive to late stage osteomyelitis, showing cortical destruction and adjacent soft tissue inflammation (Fig. 12). MRI offers a more sensitive evaluation of early disease involvement. MRI findings include T2 hyperintensity of the marrow with corresponding $\mathrm{T} 1$ hypointensity, in addition to signs of inflammation in the surrounding soft tissues (Fig. 13). Intravenous contrast should reveal avid intraosseous enhancement in osteomyelitis [27].

\section{Degenerative disease}

As the hallucal sesamoids have a true articular joint with the metatarsal head, they are susceptible to osteoarthritis [3]. Classic findings of osteoarthritis may be seen on radiographs, including
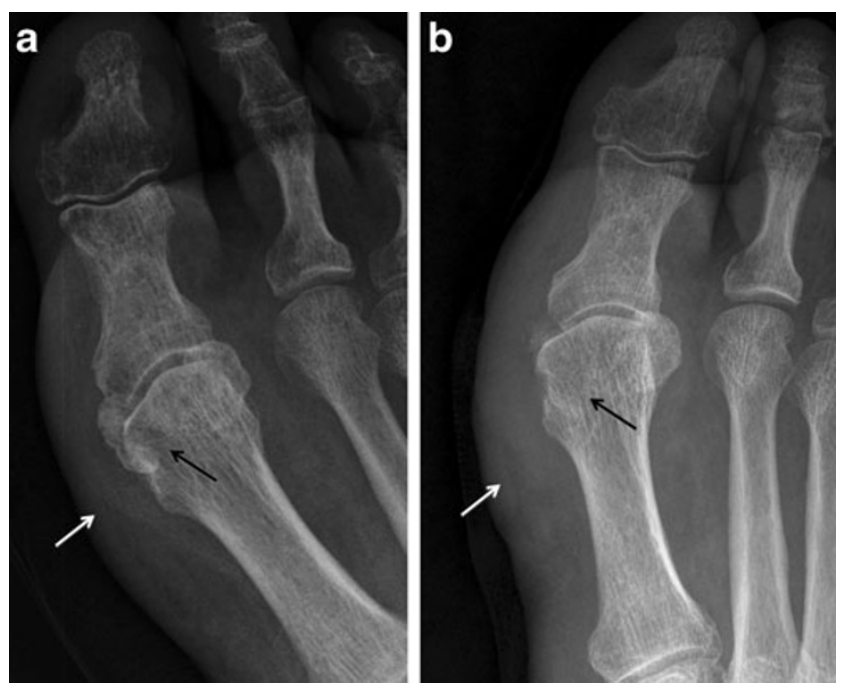

Fig. 12 Osteomyelitis. a AP radiograph in a patient with a plantar ulcer showing cortical dehiscence and destructive change at the medial sesamoid (black arrow) suggestive of osteomyelitis. Note severe adjacent soft tissue swelling (white arrow). b AP radiograph in the same patient approximately 5 weeks later with near complete destruction of the medial hallucal sesamoid (black arrow) and persistent soft tissue swelling (white arrow). The great toe was amputated
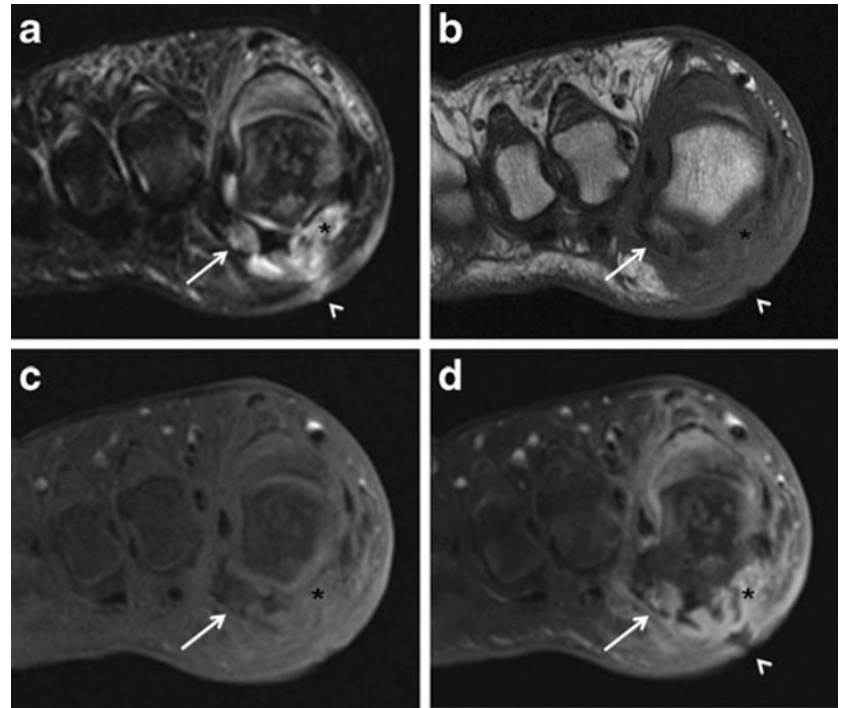

Fig. 13 Osteomyelitis in the hallucal sesamoids. Short-axis coronal T2weighted (a) and T1-weighted (b) MRIs in the same patient as Fig. 12 show complete destruction of the medial hallucal sesamoid (asterisk) and intense bone marrow oedema with $\mathrm{T} 1$ hypointensity in the lateral hallucal sesamoid (arrow). Severe soft tissue oedema is seen in the surrounding soft tissues, extending to a plantar cutaneous defect (arrowheads). Precontrast (c) and post-contrast (d) fat-saturated T1-weighted MRIs reveal intense enhancement of the medial and lateral sesamoids (asterisks, arrows) and the adjacent soft tissues. Note the ulceration in the plantar soft tissues (arrowhead, a, b, d)

loss of joint space, subchondral sclerosis and cysts, and osteophyte formation [27] (Fig. 14). In addition to these changes, MRI may reveal cartilage loss and hyperintense subchondral signal [27]. Accessory ossicles with synchondroses and those within high-use tendons may also be predisposed to degenerative changes $[10,16,28]$. CT is sensitive in the evaluation of sclerosis and fragmentation (Figs. 15 and 16), and MRI can evaluate associated marrow and soft tissue changes.

Specific ossicle-related painful syndromes

\section{Posterior ankle impingement syndrome}

Pathology attributed to the os trigonum is encompassed by the term os trigonum syndrome, which falls within the spectrum of posterior ankle impingement syndrome. Pain associated with the os trigonum may be related to degenerative changes at the synchondrosis, fracture of the posterior lateral talar process, local synovitis, flexor hallucis longus tenosynovitis or intra-articular loose bodies [10, 11, 29]. Repetitive plantar flexion predisposes to this syndrome, as seen in ballet dancers, basketball players and football players [11, 13, 29]. Clinically, patients may experience chronic or recurrent pain with stiffness, soft tissue swelling and tenderness to deep posterolateral palpation $[10,11,29]$. On imaging, radiographs demonstrate the presence or absence of an os trigonum, soft tissue swelling and infiltration of fat (Fig. 17). CT may demonstrate fractures 

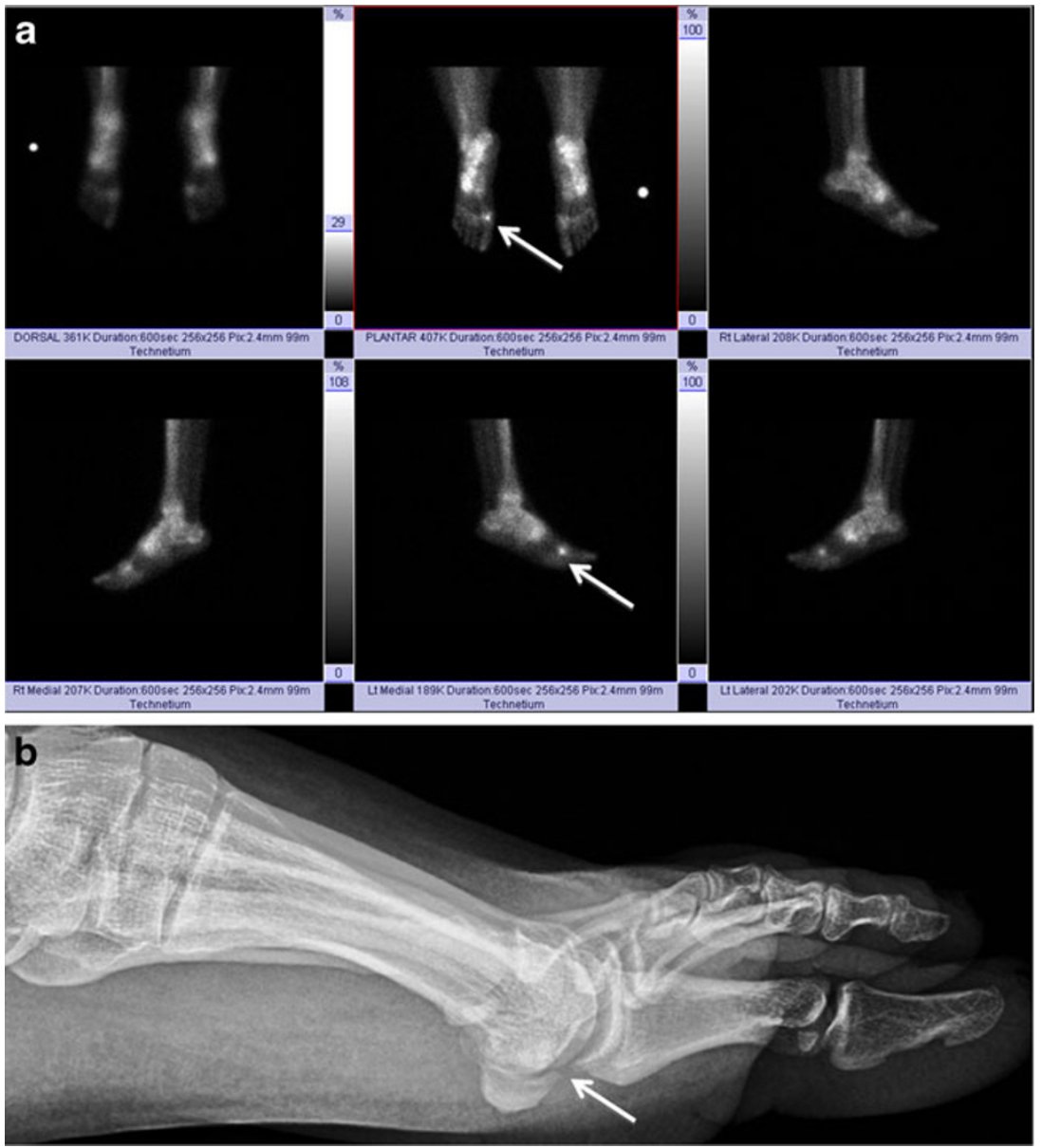

Fig. 14 Osteoarthritis. Bone scan of the bilateral feet (a) shows nonspecific but intense tracer uptake localising to the medial hallucal sesamoid (arrows). Lateral radiograph at the first toe (b) reveals joint space narrowing and osteophyte formation at the medial sesamoid-metatarsal articulation (arrow), consistent with osteoarthritis

synovitis and tenosynovitis are readily apparent [11, 29] (Fig. 16).

\section{Painful os peroneum syndrome}

Fracture or attrition of the os peroneum and degeneration or tearing of the peroneus longus tendon at the site of the ossicle
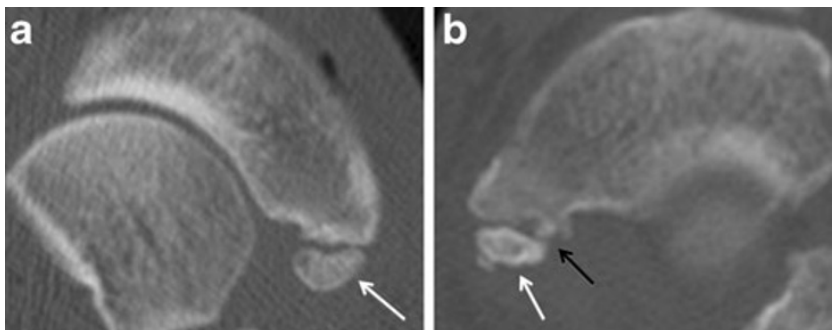

Fig. 15 Degeneration at a synchondrosis. a Long-axis axial CT image shows an apparently normal type II accessory navicular (arrow) with a preserved synchondrosis with the navicular tubercle. b In comparison, this long-axis axial CT image of a different foot depicts increased sclerosis and fragmentation of a type II accessory navicular (white arrow) and fragmentation of the navicular tubercle at the synchondrosis (black arrow) consistent with degenerative change
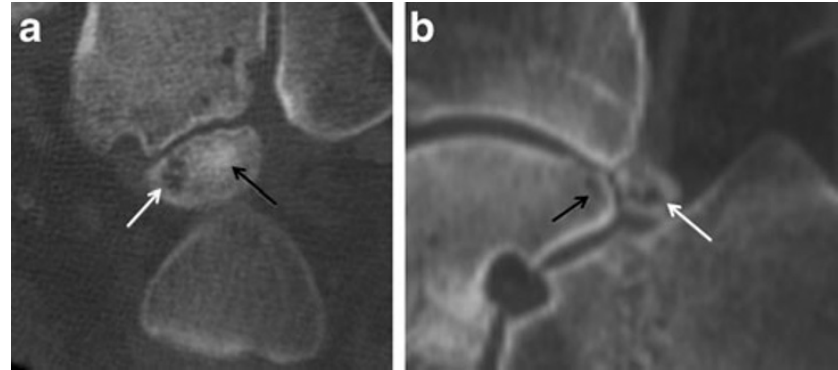

Fig. 16 Degeneration at a synchondrosis. a Long-axis axial CT image shows increased sclerosis (black arrow) and subchondral cyst formation in an os trigonum. b Sagittal CT image reveals subchondral cyst formation in the talus (black arrow) and os trigonum (white arrow) across the synchondrosis, due to degenerative change 

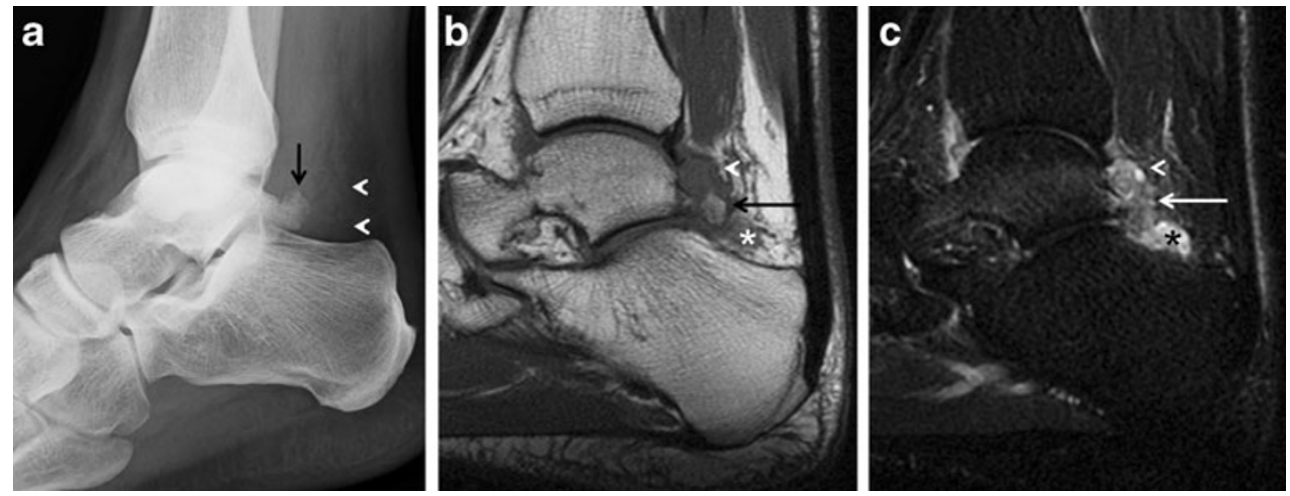

Fig. 17 Os trigonum syndrome. a Lateral radiograph of the ankle demonstrates an os trigonum (arrow) and posterior soft-tissue prominence and infiltration of the pre-Achilles fat (arrowheads). Sagittal T1-weighted (b)

may cause painful os peroneum syndrome [28], which presents as lateral pain and tenderness along the course of the peroneus longus tendon. Radiography and CT will demonstrate the presence of an os peroneum, displacement from its normal location, fracture or distraction of a bipartite sesamoid. As mentioned previously, proximal migration of the os peroneum indicates a tear of the peroneus longus tendon, and wide separation $(>2 \mathrm{~mm})$ of os peroneum fragments is less likely to represent a normal bipartite os peroneum [23]. MRI may reveal tendinosis and abnormal bone marrow signal within the ossicle and the adjacent osseous structures (Fig. 18). Ultrasound may also be used to locate tendon tears and tenosynovitis associated with the os peroneum [23].

\section{Painful accessory navicular}

A symptomatic accessory tarsal navicular is most commonly seen with a type II accessory navicular and is thought to be the result of altered biomechanics, presenting as shoe irritation and pain localising to the navicular bone $[15,16]$. Clinical symptoms and STIR (c) MRIs show bone marrow oedema (arrows) in the os trigonum, posterior recess nodularity and thickening (arrowheads), and a joint effusion (asterisk). The patient was a runner with clinical posterior impingement

may be attributed to tension and repetitive shearing stress at the synchondrosis from the posterior tibial tendon, causing disruption of the synchondrosis, posterior tibial tenosynovitis and even osteonecrosis $[13,16]$. CT may demonstrate degenerative changes at the synchondrosis and abnormal osseous density in detail. Technetium bone scan may reveal increased uptake in a symptomatic accessory navicular, although this finding may not be specific [13]. On MRI, there may be abnormal signal within the ossicle, in the synchondrosis and navicular tubercle, within the adjacent soft tissues and in the posterior tibial tendon $[13,16]$ (Fig. 19).

\section{Painful os intermetatarseum}

Compared with the aforementioned ossicles, the os intermetatarseum is less commonly reported as a cause of pain. However, compression of the superficial or deep peroneal nerve by this ossicle has been described as a source of dorsal foot pain $[13,30]$. Patients present with pain and/or numbness at the dorsum of the foot that is exacerbated by standing or jumping,
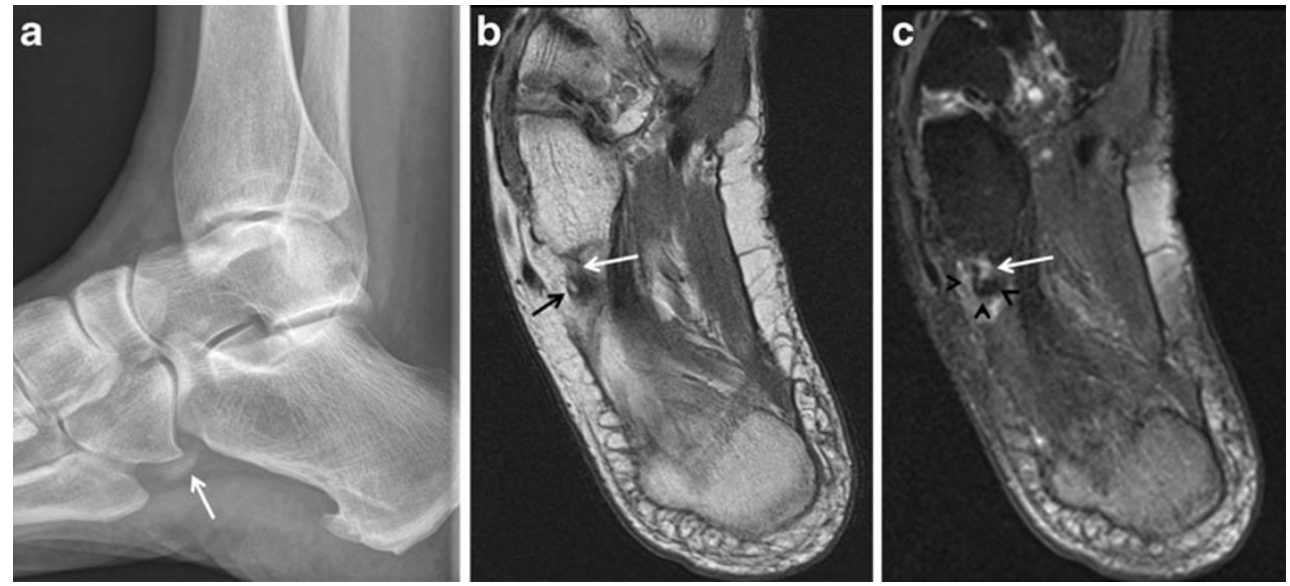

Fig. 18 Painful os peroneum syndrome. a Lateral radiograph of the ankle demonstrates the presence of an os peroneum (white arrow). Axial proton density-weighted (b) and T2-weighted fat-saturated (c) MRIs of the ankle show focal tendinosis at the peroneus longus tendon (white arrows) just distal to the os peroneum (black arrow) and surrounding soft tissue oedema (arrowheads). These findings corroborate a painful os peroneum syndrome 

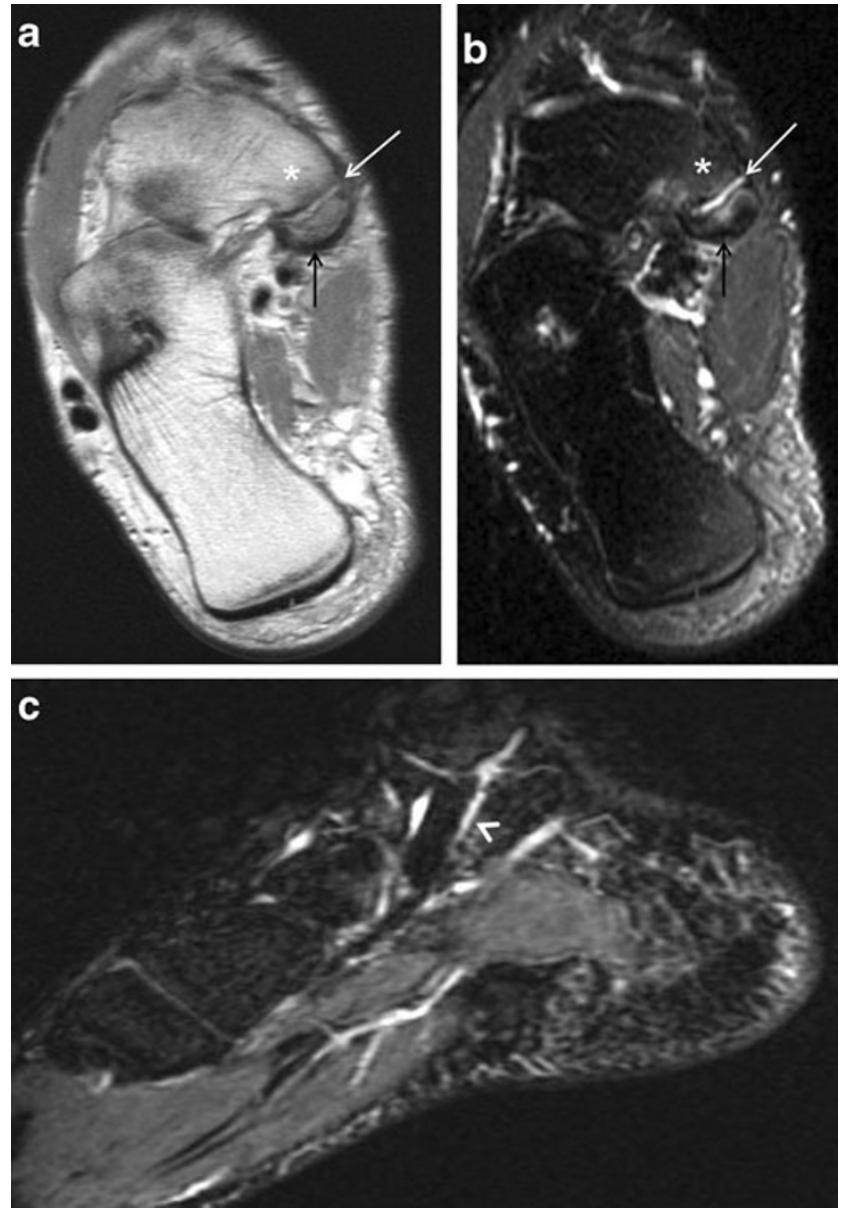

Fig. 19 Symptomatic accessory navicular. Axial proton density-weighted (a) and T2-weighted fat-saturated (b) MRIs demonstrate abnormal marrow signal in a type II accessory navicular (black arrows), adjacent navicular tubercle (asterisks) and synchondrosis (white arrows). In addition, sagittal STIR MRI (c) reveals posterior tibial tenosynovitis (arrowhead). The patient presented with medial foot pain

and tenderness to palpation at the first intermetatarsal interspace $[13,30]$. Scintigraphy may reveal increased radiotracer uptake in a symptomatic os intermetatarseum [13].

\section{Conclusion}

Sesamoids and accessory ossicles seen in the foot vary widely in their prevalence and appearance. Although the clinical significance of these osseous structures is probably minor, clinicians very commonly ask about these bones, and this may incite an unnecessary work-up. Therefore, becoming familiar with these bones is important to prevent misinterpreting them as fractures, a common error. Finally, it may be very difficult to distinguish between incidental or clinically irrelevant bones and truly symptomatic ones. Radiological studies including radiography, ultrasound, scintigraphy, CT and MRI provide useful information regarding the presence and pathology involving these bones, and should be used in concert with clinical findings to guide patient management.

Disclosures A.G. is the President of Boston Imaging Core Lab (BICL), LLC, and a consultant to TissueGene, Sanofi-Aventis, and Merck Serono. F.W.R. is a shareholder of BICL, and is a consultant to Merck Serono and the National Institute of Health. Other authors have nothing to disclose.

No funding was received for this work.

Open Access This article is distributed under the terms of the Creative Commons Attribution License which permits any use, distribution, and reproduction in any medium, provided the original author(s) and the source are credited.

\section{References}

1. Sarrafian SK (1993) Osteology. In: Sarrafian SK (ed) Anatomy of the foot and ankle. Lippincott, Philadelphia, pp 89-112

2. Muneral PV, Dominguez G, Reina M, Trujillo P (2007) Bipartite hallucal sesamoid bones: relationship with hallux valgus and metatarsal index. Skeletal Radiol 36:1043-1050

3. Potter HG, Pavlov H, Abrahams TG (1992) The hallux sesamoids revisited. Skeletal Radiol 21:437-444

4. Coskun N, Yuksel M, Cevener M, Arican RY, Ozdemir H, Bircan O et al (2009) Incidence of accessory ossicles and sesamoid bones in the feet: a radiographic study of the Turkish subjects. Surg Radiol Anat 31:19-24

5. Roukis TS, Hurless JS (1996) The hallucal interphalangeal sesamoid. J Foot Ankle Surg 35:303-308, discussion 72

6. Davies MB, Dalal S (2005) Gross anatomy of the interphalangeal joint of the great toe: implications for excision of plantar capsular accessory ossicles. Clin Anat 18:239-244

7. Leung HB, Wong WC (2002) Irreducible dislocation of the hallucal interphalangeal joint. Hong Kong Med J 8:295-299

8. Woon CY (2010) Dislocation of the interphalangeal joint of the great toe: is percutaneous reduction of an incarcerated sesamoid an option?: A report of two cases. J Bone Joint Surg Am 92:1257-1260

9. Lawson JP (1994) International skeletal society lecture in honor of Howard D. Dorfman. Clinically significant radiologic anatomic variants of the skeleton. AJR Am J Roentgenol 163:249-255

10. Karasick D, Schweitzer ME (1996) The os trigonum syndrome: imaging features. AJR Am J Roentgenol 166:125-129

11. Lee JC, Calder JD, Healy JC (2008) Posterior impingement syndromes of the ankle. Semin Musculoskelet Radiol 12:154-169

12. Anwar R, Nicholl JE (2005) Non-union of a fractured os trigonum. Injury $36: 267-270$

13. Miller TT (2002) Painful accessory bones of the foot. Semin Musculoskelet Radiol 6:153-161

14. Sobel M, Pavlov H, Geppert MJ, Thompson FM, DiCarlo EF, Davis WH (1994) Painful os peroneum syndrome: a spectrum of conditions responsible for plantar lateral foot pain. Foot Ankle Int 15:112-124

15. Stoller DW (2007) Magnetic resonance imaging in orthopaedics and sports medicine, 3rd edn. Wolters Kluwer/Lippincott Williams \& Wilkins, Philadelphia

16. Miller TT, Staron RB, Feldman F, Parisien M, Glucksman WJ, Gandolfo LH (1995) The symptomatic accessory tarsal navicular bone: assessment with MR imaging. Radiology 195:849-853

17. Boya H, Ozcan O, Tandogan R, Gunal I, Arac S (2005) Os vesalianum pedis. J Am Podiatr Med Assoc 95:583-585 
18. Wilson TC, Wilson RC, Ouzounov KG (2011) The symptomatic os vesalianum as an uncommon cause of lateral foot pain: a case report. J Am Podiatr Med Assoc 101:356-359

19. Tsuruta T, Shiokawa Y, Kato A, Matsumoto T, Yamazoe Y, Oike T et al (1981) Radiological study of the accessory skeletal elements in the foot and ankle. Nihon Seikeigeka Gakkai Zasshi 55:357-370

20. Cilli F, Akcaoglu M (2005) The incidence of accessory bones of the foot and their clinical significance. Acta Orthop Traumatol Turc 39: 243-246

21. Mellado JM, Ramos A, Salvado E, Camins A, Danus M, Sauri A (2003) Accessory ossicles and sesamoid bones of the ankle and foot: imaging findings, clinical significance and differential diagnosis. Eur Radiol 13(Suppl 4):L164-L177

22. Kurklu M, Kose O, Yurttas Y, Oguz E, Atesalp AS (2010) Anterosuperior calcaneal process fracture or OS calcaneus secundarius? Am J Phys Med Rehabil 89:522

23. Brigido MK, Fessell DP, Jacobson JA, Widman DS, Craig JG, Jamadar DA et al (2005) Radiography and US of os peroneum fractures and associated peroneal tendon injuries: initial experience. Radiology 237:235-241
24. Kose O (2009) Os vesalianum pedis misdiagnosed as fifth metatarsal avulsion fracture. Emerg Med Australas 21:426

25. Karasick D (1994) Fractures and dislocations of the foot. Semin Roentgenol 29:152-175

26. Mellado JM, Ramos A, Salvadó E, Camins A, Danús M, Saurí A (2003) Accessory ossicles and sesamoid bones of the ankle and foot: imaging findings, clinical significance and differential diagnosis. Eur Radiol 13(Suppl 6):L164-L177

27. Karasick D, Schweitzer ME (1998) Disorders of the hallux sesamoid complex: MR features. Skeletal Radiol 27:411-418

28. Wang XT, Rosenberg ZS, Mechlin MB, Schweitzer ME (2005) Normal variants and diseases of the peroneal tendons and superior peroneal retinaculum: MR imaging features. Radiographics 25:587602

29. Hillier JC, Peace K, Hulme A, Healy JC (2004) Pictorial review: MRI features of foot and ankle injuries in ballet dancers. Br J Radiol 77: $532-537$

30. Nakasa T, Fukuhara K, Adachi N, Ochi M (2007) Painful os intermetatarseum in athletes: report of four cases and review of the literature. Arch Orthop Trauma Surg 127:261-264 